\title{
Use of psychotropic drugs in homes for the aged in Bergen, Norway: A comparative study
}

\author{
Harald A. Nygaard, MD, PhD and Mala Naik, MD \\ Division for Geriatric Medicine, Department of Public Health and Primary Health Care, University of Bergen, Norway \\ Correspondence to: Harald A. Nygaard, Division for Geriatric Medicine, Department of Public Health and Primary Health Care, \\ University of Bergen, Ulriksdal 8 c, N-5009 Bergen \\ e-mail: harald.nygaard@isf.uib.no
}

\begin{abstract}
Study objectives: To compare the regular use of psychotropic drugs in 1985 and 1996 in homes for the aged in Bergen, Norway and to study the relation between age, gender, mental impairment and certain behaviour traits and psychotropic drug use.

Design: A point prevalence survey performed on two occasions in 1985 and 1996.

Setting: All regularly used psychotropic drugs and demographic information were collected from the case notes. Mental capacity, which was assessed by means of the Clinical Dementia Rating Scale (CDR), and behaviour were registered by a trained nurse.

Participants: Thirteen representative homes for the aged with a total of 339 residents in 1985 and 286 residents in 1996.

Main results: The was a significant increased use of psychotropic drugs from 1985 to $1996,48 \%$ to $61 \%$ of the residents $(\mathrm{p}=0.002)$. The use of anxiolytics and antidepressants increased significantly $(5 \%$ to $14 \%, \mathrm{p}=0.0004$ and $12 \%$ to $23 \%, \mathrm{p}=0.0005$, respectively), while antipsychotics and hypnotics remained stable $(24 \%$ on both occasions and $22 \%$ and $27 \%$, respectively). The use of anxiolytics and neuroleptics was associated with anxiety, wandering and aggressive behaviour. Anxiolytics were more frequently use by mentally unimpaired residents. A substantial number of passive and apathetic residents were treated inappropriately with psychotropic drugs.

Conclusion: During several years educational programs for nurses and physicians have been carried out to improve the general care and drug treatment of the elderly, especially with regard to psychotropic drugs. The anticipated changes in the use of psychotropic drugs have not been fulfilled.
\end{abstract}

Key words: Long term care facilities; psychotropic drugs; non-cognitive symptoms; mental impairment

\section{INTRODUCTION}

Most elderly people want to live in their own homes as long as possible. To enable proper care for the elderly, home based services have been improved over the last decades. Sheltered accommodations are intended for elderly with minor or moderate care needs who want to live independently, and homes for the aged for those who want to live in an institutional setting. Persons who are heavily dependent on continuous nursing care are cared for in nursing homes.

The city of Bergen, the second largest in Norway, has approximately 220,000 inhabitants, of who $12 \%$ are 70 years or older. In 1995 there were 638 places in homes for the aged and 1818 places in nursing homes. Compared to 1985 this constituted a reduction of $19 \%$ and an increase of $29 \%$, respectively. The reduced capacity in homes for the aged was due to closing down of five institutions. In 1985, 31\% of residents in all homes for the aged were moderately or severely mentally impaired (1).
Treatment with psychotropic drugs increases risk for the residents, e.g. propensity of falling, and fractures (2). The use of psychotropic drugs in institutions for the elderly is generally reported to be high, and absent appropriate diagnoses $(3,4)$. Symptoms seem to prompt the prescription of a psychotropic drug. E.g. neuroleptics is particularly associated with "disrupted behaviour" (3-6).

In 1985 it was found that $23 \%$ of residents in homes for the aged in the city used neuroleptics regularly (7). During the past years there has been a general focus upon alternative treatment strategies for mentally impaired persons and on the deleterious effects which many of the psychotropic drugs may evolve in the elderly $(8,9)$. Curtailing the use of psychotropic drugs in institutionalised elderly is both essential and possible $(10,11)$. Post graduate courses on geriatric medicine for general practitioners who predominately are responsible for the medical services in homes for the aged and nursing homes, have been accomplished. Local authorities have yearly carried out several seminars 
for nurses and nurses aids who work in nursing homes and in homes for the aged. Proper care for mentally impaired and drug use in the elderly has been a main topic in these sessions. Furthermore, for several years a nation wide program devoted to every aspect of dementia assessment and care, has been at work.

On this background it was of interest to study whether there had been any changes regarding the use of psychotropic drugs in homes for the aged in the city between 1985 and 1996.

\section{MATERIAL AND METHODS}

In 1985 a point prevalence study concentrating on mental capacity, work load and the regular consumption of psychotropic drugs was performed in the homes for the aged in Bergen. During the first two weeks of 1996 a second study was carried out. The procedures and methods, which were identical, have previously have been described in detail (1). Mental capacity was assessed by means of the Clinical Dementia Rating scale (CDR) $(1,12)$, which is a global rating scale consisting of six items: memory, orientation, judgement and problem solving, community affairs, home and hobbies, and personal care. Patients are assigned a rating of healthy $(\mathrm{CDR}=0)$, "senescent forgetfulness" $(\mathrm{CDR}=0.5)$, mild $(\mathrm{CDR}=1)$, moderate $(\mathrm{CDR}=2)$ or severe $(\mathrm{CDR}=3)$ mental impairment. In this study CDR 0 and 0.5 and CDR 2 and 3 were grouped together. For present purpose only the item "behaviour" from the work load scale was chosen. It is scored on a four point scale: inconspicuous, apathetic/ passive, anxious, wandering, restless, restrained, restless/aggressive (13). Psychotropic drugs were classified according to the Anatomical Therapeutic Chemical Classification Code (ATC classification); neuroleptics (antipsychotics) (N 05A), anxiolytics (N 05 B), hypnotics/sedatives (N 05 C) and antidepressants (N $06 \mathrm{~A})(14)$.

Demographic information was obtained from the case notes. Behaviour and mental functions (CDR) were evaluated by nurses who were in daily contact with the residents, and thus well capable to perform the assessment. Prior to registration they had received a written instruction in the use of the CDR.

Non-parametric statistical methods were used. The associations between drug use, gender, age, mental status, behaviour and year of registration were investigated using logistic regression analyses, where the study drug (dependent variable) was coded "0" for non-user, and "1" for user.

In 1985 all 27 homes for the aged in the city of Bergen took part in the study. For the present study 13 representative homes were invited to take part in the survey. An analysis of the data from 1985 comparing residents from homes being studied both in 1985/96 and those studied only in 1985 , revealed no statistical differences with regard to gender distribution, marital state, age, duration of stay, mental capacity or behavi- our. Thus the 13 homes studied in 1996 are considered representative for all homes for the aged in the city. All comparisons between 1985 and 1996 were performed on the same institutions.

\section{RESULTS}

Demographic characteristics, mental capacity, behaviour, and psychotropic drug consumption in 1985 and 1996 are shown in Table 1. The median stay increased by eight months overall, but the change was more pronounced for mentally unimpaired residents (CDR $0-0.5)$ (27. 8 and 37.3 months in 1985 and 1996 respectively, $\mathrm{z}=2.59, \mathrm{p}=0.01$ ). In 1996 significantly more residents used psychotropic drugs on a regular schedule $(61 \%$ versus $48 \%$, Fishers exact test, $\mathrm{p}=$ 0.002 ). In 1985 the mentally impaired constituted $46 \%$ of all residents and accounted for $52 \%$ of the psychotropic users. In 1996 the corresponding figures were $61 \%$ and $59 \%$.

Table 1. Demographic characteristics, mental and behavioural states, and drug use among residents of homes for the aged, Bergen 1985 and 1996 (\%).

\begin{tabular}{|c|c|c|c|}
\hline & $\begin{array}{c}1985 \\
\mathrm{n}=339\end{array}$ & $\begin{array}{c}1996 \\
n=286\end{array}$ & $\mathrm{p}$ \\
\hline Age (years, median) & 84 & 87 & $<0.0001^{1}$ \\
\hline range & $53-97$ & $55-104$ & \\
\hline Stay (months, median) & $30^{2}$ & 38 & $0.04^{1}$ \\
\hline range & $0,03-393$ & $0,2-392$ & \\
\hline Male/Female & $84 / 254$ & $62 / 224^{3}$ & $0.4^{4}$ \\
\hline Marital state & & & $0.007^{3,5}$ \\
\hline Married & $31(9)$ & $19(7)$ & \\
\hline Widows/widower & $213(63)$ & $214(75)$ & \\
\hline Unmarried/divorced & $94(28)$ & 53 (19) & \\
\hline CDR-group & & & $0.0004^{5}$ \\
\hline CDR 0-0.5 & $184(54)$ & $111(39)$ & \\
\hline CDR 1 & $59(17)$ & $74(26)$ & \\
\hline CDR 2-3 & $96(28)$ & $101(35)$ & \\
\hline Behaviour & & & 0.26 \\
\hline No disturbance & $144(43)$ & $108(38)$ & \\
\hline Apathetic/anxious & 149 (44) & $127(44)$ & \\
\hline Aggressive/wandering & $46(14)$ & $51(18)$ & \\
\hline Use of antipsychotics & & & $1.0^{4}$ \\
\hline No & $258(76)$ & $217(76)$ & \\
\hline Yes & $81(24)$ & $68(24)$ & \\
\hline Use of anxiolytics & & & $0.0004^{3,4}$ \\
\hline No & $321(95)$ & $246(86)$ & \\
\hline Yes & $18(5)$ & 39 (14) & \\
\hline Use of hypnotics & & & $0.2^{3,4}$ \\
\hline No & $264(78)$ & $209(73)$ & \\
\hline Yes & $75(22)$ & $76(27)$ & \\
\hline Use of antidepressants & & & $0.0005^{4}$ \\
\hline No & $299(88)$ & $221(78)$ & \\
\hline Yes & $40(12)$ & $64(23)$ & \\
\hline Any psychotropic drug & & & $0.002^{4}$ \\
\hline No & $176(52)$ & $112(39)$ & \\
\hline Yes & $163(48)$ & $173(61)$ & \\
\hline
\end{tabular}

\footnotetext{
${ }^{1}$ Mann-Whitney test

${ }^{2}$ Information missing in 3 cases

${ }^{3}$ Information missing in 1 case

${ }^{4}$ Fishers exact test

${ }^{5}$ Chi-square test

${ }^{6}$ Information missing in 7 cases
} 
The frequency of the various drugs used is shown in table 2. Use of combinations of two or more drugs was slightly higher in 1996, 37\% and 27\% respectively, Fisher exact test, $\mathrm{p}=0.06)$. Forty-three percent of all prescriptions for antipsychotics were combinations. For anxiolytics, hypnotics and antidepressants the figures were $60 \%, 36 \%$ and $64 \%$ respectively. In 1996 $31 \%$ of all prescribed antidepressants were drugs with strong anti-cholinergic effects (amitriptylin and doxepin).

Table 2. The most frequently used psychotropic drugs in homes for the aged, Bergen, 1985 and 1996. ( ) = percentage of all prescriptions in each year.

\begin{tabular}{lcc}
\hline Drugs & 1985 & 1996 \\
\hline Antipsychotics (N 05 A) & $(39 \%)^{1}$ & $(29 \%)^{1}$ \\
Phenothiazines & 38 & 30 \\
Metylperon & 21 & 12 \\
Haloperidol & 8 & 9 \\
Thioxanthenes & 20 & 8 \\
Combinations, antipsychotics & - & 9 \\
Anxiolytics (N 05 B) & $(9 \%)^{1}$ & $(15 \%)^{1}$ \\
Diazepam/Chlordiazepoxide & 18 & 32 \\
Oxazepam & 1 & 3 \\
Hydroxyzin & 0 & 2 \\
Combinations, anxiolytics & - & 1 \\
Hypnotics (N 05 C) & $(34 \%)^{1}$ & $(29 \%)^{1}$ \\
Nitrazepam & 50 & 46 \\
Flurazepam & 6 & -2 \\
Triazolam & 6 & -2 \\
Meprobamate & 6 & -2 \\
Flunitrazepam & 4 & 25 \\
Chlormetiazol & 0 & 1 \\
Antidepressants (N 06 A) & $(18 \%)^{1}$ & $(27 \%)^{1}$ \\
Amitriptylin & 16 & 12 \\
Nortriptylin & 0 & 6 \\
Doxepin & 15 & 8 \\
Other TCA & 7 & 1 \\
Mianserin & 3 & 10 \\
Combinations, antidepressants & - & $5^{4}$ \\
Paroxetin & $-{ }^{1}$ & 19 \\
Fluvoxamin & $-{ }^{1}$ & 1 \\
Meklobemid & $-{ }^{1}$ & 2 \\
\hline Number & &
\end{tabular}

${ }^{1}$ Number of drugs in Table 1 and Table 2 do not correspond completely because some patients receive combinations of drugs from the same class

${ }^{2}$ Not available

${ }^{3} \mathrm{TCA}=$ tricyclic antidepressants

${ }^{4}$ thereof 4 with amitriptylin

Drug consumption related to year, gender, age, mental state and "behaviour" is shown in table 3. The influence of these factors on drug use was subsequently studied using logistic regression analyses (table 4). The probability for being treated with an anxiolytic or an antidepressant drug was three times and two times higher, respectively, in 1996 than in 1985. Residents using one of the two drugs were three times as likely to use the other one than non-users. In general the probability for drug treatment decreased with age.
Furthermore, the probability for a mentally unimpaired resident to receive an anxiolytic was double that of a mentally impaired resident.

There was no association between drug use and mental impairment, and a strong association between psychotropic drug treatment and behaviour symptoms. However, mentally impaired residents constituted the majority of the aggressive and wandering patients. Seventy-two percent of the aggressive and wandering residents belonged to CDR 2-3. Among anxious residents approximately $1 / 3$ was assigned to each of the CDR groups. Among apathetic residents 50\% belonged to CDR $2-3$, and $74 \%$ of behaviourally inconspicuous residents belonged to CDR 0-0.5. Regardless of whether the residents were apathetic, anxious or aggressive/wandering, there was an increased probability of receiving an antipsychotic, anxiolytic or antidepressant drug.

\section{DISCUSSION}

Several limitations should be taken into consideration when interpreting the results. The "behaviour" item used is rather rough. Better scales are now available. However, to compare the two studies, identical instruments were preferred, and the 1985 survey used the instrument in question. Due to this, e.g. depression was not assessed. A geriatric workup is rarely performed prior to, and it is not a prerequisite for admission to homes for the aged. Hence medical diagnoses are incomplete and they were not included here. This is of particular importance with regard to diagnosing dementia. Mental status was therefore assessed by means of CDR by a nurse who knew the patient. We have previously found good agreement between mental state evaluation conducted by a physician and by a nurse using the CDR (kappa = 0.79) (1).

In Bergen, homes for the aged are increasingly used as a domicile for mentally impaired elderly. The changes from 1985 to 1996 are mainly due to an increasing number of mentally impaired elderly without severe behaviour problems. The increase is not due to development of mental impairment in residents who had lived in the home for years (15). However, homes for the aged were established for and staffed with regard to elderly without substantial caring needs. Hence inappropriate placement of elderly persons who need the level of care which is provided in a nursing home, will certainly have an impact on the internal environment.

From 1985 to 1996 there was a significant increase in the use of anxiolytics and antidepressants, and the proportion being treated with combinations of several psychotropic drugs also increased. It is a general opinion that psychotropic drug consumption in long term care facilities for the elderly is unnecessarily high, that they frequently are prescribed inappropriately, and in many cases with harmful consequences (2-4). On this background it has become a general intention to 
Table 3. Probabilities (odds ratio (OR)) for treatment with psychotropic drugs in residents of homes for the aged.

\begin{tabular}{|c|c|c|c|c|c|c|c|c|c|c|c|c|c|c|c|c|}
\hline & \multicolumn{4}{|c|}{ Antipsychotics } & \multicolumn{4}{|c|}{ Anxiolytics } & \multicolumn{4}{|c|}{ Hypnotics } & \multicolumn{4}{|c|}{ Antidepressants } \\
\hline & $\begin{array}{l}\text { User } \\
(149)\end{array}$ & $\begin{array}{l}\text { Non-use } \\
(475)\end{array}$ & $\mathrm{OR}^{1}$ & $95 \% \mathrm{CI}$ & $\begin{array}{r}\text { User } \\
(57)\end{array}$ & $\begin{array}{c}\text { Non-user } \\
(567)\end{array}$ & $\mathrm{OR}^{1}$ & $95 \% \mathrm{CI}$ & $\begin{array}{l}\text { User } \\
(151)\end{array}$ & $\begin{array}{c}\text { Non-us } \\
(473)\end{array}$ & $\mathrm{OR}^{1}$ & $95 \% \mathrm{CI}$ & $\begin{array}{l}\text { User } \\
(104)\end{array}$ & $\begin{array}{c}\text { Non-user } \\
(520)\end{array}$ & $\mathrm{OR}^{1}$ & $5 \% \mathrm{CI}$ \\
\hline \multicolumn{17}{|l|}{ Year } \\
\hline 1985 & 81 & 258 & 1.0 & & 18 & 321 & 1.0 & & 75 & 264 & 1.0 & & 40 & 299 & 1.0 & \\
\hline 1996 & 68 & 217 & 1.0 & $0.7-1.5$ & 39 & 246 & 2.8 & $1.5-5.4$ & 76 & 209 & 1.3 & $0.9-1.9$ & 64 & 221 & 1.2 & $0.4-3.4$ \\
\hline \multicolumn{17}{|l|}{ Gender } \\
\hline Male & 31 & 115 & 1.0 & & 12 & 134 & 1.0 & & 23 & 123 & 1.0 & & 16 & 130 & 1.0 & \\
\hline Female & 118 & 359 & 1.2 & $0.8-2.0$ & 45 & 432 & 1.2 & $0.6-2.5$ & 127 & 350 & 1.9 & $1.2-3.3$ & 88 & 389 & 1.8 & $1.0-3.5$ \\
\hline \multicolumn{17}{|l|}{ Age groups ${ }^{2}$} \\
\hline$<80$ & 43 & 73 & 1.0 & & 17 & 99 & 1.0 & & 28 & 88 & 1.0 & & 22 & 94 & 1.0 & \\
\hline $80-89$ & 73 & 274 & 0.5 & $0.3-0.7$ & 27 & 320 & 0.5 & $0.3-1.0$ & 78 & 269 & 0.9 & $0.5-1.6$ & 61 & 286 & 0.9 & $0.5-1.7$ \\
\hline $90+$ & 32 & 128 & 0.4 & $0.2-0.8$ & 12 & 148 & 0.5 & $0.2-1.1$ & 45 & 115 & 1.2 & $0.7-2.2$ & 21 & 139 & 0.7 & $0.3-1.3$ \\
\hline \multicolumn{17}{|l|}{ CDR-groups } \\
\hline CDR 0-0.5 & 55 & 239 & 1.0 & & 30 & 264 & 1.0 & & 80 & 214 & 1.0 & & 46 & 248 & 1.0 & \\
\hline CDR 1 & 27 & 106 & 1.1 & $0.6-1.9$ & 9 & 124 & 0.6 & $0.3-1.4$ & 37 & 96 & 1.0 & $0.6-1.7$ & 25 & 108 & 1.3 & $0.7-2.2$ \\
\hline CDR 2-3 & 67 & 130 & 2.2 & $1.5-3.5$ & 18 & 179 & 0.9 & $0.5-1.7$ & 34 & 163 & 0.56 & $0.3-0.9$ & 33 & 164 & 1.1 & $0.6-1.8$ \\
\hline \multicolumn{17}{|l|}{ Behaviour } \\
\hline Inconspicuous & 26 & 225 & 1.0 & & 13 & 238 & 1.0 & & 60 & 191 & 1.0 & & 22 & 229 & 1.0 & \\
\hline Apathetic/passive & 31 & 86 & 3.1 & $1.7-5.8$ & 6 & 111 & 1.0 & $0.3-2.9$ & 22 & 95 & 0.7 & $0.4-1.3$ & 20 & 97 & 2.2 & $1.1-4.3$ \\
\hline Anxious & 47 & 112 & 3.6 & $2.1-6.4$ & 24 & 135 & 3.3 & $1.5-7.2$ & 49 & 110 & 1.4 & $0.9-2.3$ & 44 & 115 & 4.0 & $2.2-7.3$ \\
\hline $\begin{array}{l}\text { Aggressive/ } \\
\text { wandering }\end{array}$ & 45 & 52 & 7.5 & $4.1-13.8$ & 14 & 83 & 3.1 & $1.3-7.4$ & 20 & 77 & 0.8 & $0.4-1.5$ & 18 & 79 & 2.4 & $1.1-4.9$ \\
\hline
\end{tabular}

reduce the utilisation of psychotropics in the institutionalised elderly. In the USA legal regulations have contributed to a significant reduction in the use of neuroleptic drugs (16). However, as in our study, there has been an increased use of anxiolytics, and the use of anticholinergic antidepressants persists (17). In Germany Weyerer et al. (18) recorded an increased use of neuroleptics and antidepressants from 1988 to 1992 in homes for the aged (from 13\% to 23\% and from $9 \%$ to $13 \%$ of the residents, respectively), and anxiloytic use was slightly reduced (from 13\% to $11 \%$ ). Many factors influence the prescription of drugs in institutionalised elderly, factors which may differ between countries, making comparison across borders difficult.

Antipsychotics have a modest effect on noncognitive symptoms in demented patients (19). Our results also emphasise that antipsychotics are directed toward conspicuous behaviour (non-cognitive symptoms), a finding which is consistent with other studies $(6,20,21)$. However, other diseases may also be accompanied by "behaviour" symptoms triggering treatment with psychotropic drugs, e.g. stroke $(22,23)$, depression and anxiety states. The frequent and inexplicable use of psychotropics in apathetic and passive residents must be considered as inappropriate.

We were not able to control for depressive states in this study. The prevalence of depression is considered high in nursing homes (24), and there is reason to believe that the same holds true for homes for the aged. To our knowledge this has not been studied in Norwe- gian long term care institutions. One might consider that the increased use of antidepressants is for depressive states. However, in Scandinavia the SSRIs have been advocated as drug of first choice when there is an indication for drug treatment of non-cognitive symptoms, and caution has been given regarding neuroleptic treatment (8), a recommendation which obviously has not been adopted so wholeheartedly as anticipated.

There was a tendency that anxiolytics were more frequently used in mentally unimpaired residents. We have no information whether this treatment was started in the home or not. One explanation might be that mentally unimpaired elderly need anxiolytic and sedating drug treatment to hold up in an environment which is heavily influenced by mentally impaired residents. Still, long acting benzodiazepines are the most frequently used drug in this category.

\section{CONCLUSIONS}

From 1985 to 1996 there has been an clear change in the use of psychotropic drugs in Bergen. Anxiolytics are frequently used in mentally unimpaired residents, but also for apathetic, anxious and wandering residents, and in combination with other psychotropic drugs. There has been a substantial increase in the use of antidepressants, which also is recommended for non-cognitive symptoms. However, the anticipated changes in the use of psychotropic drugs have not been fulfilled. 
Table 4. Logistic regression analyses for factors influencing the use of antipsychotics, anxiolytics, hypnotics/sedatives and antidepressants in homes for the aged.

\begin{tabular}{|c|c|c|c|c|c|c|c|c|c|c|c|c|c|c|c|c|}
\hline & \multicolumn{4}{|c|}{ Antipsychotics } & \multicolumn{4}{|c|}{ Anxiolytics } & \multicolumn{4}{|c|}{ Hypnotics } & \multicolumn{4}{|c|}{ Antidepressants } \\
\hline & beta & S.E. & $\mathrm{AOR}^{1}$ & $95 \% \mathrm{CI}$ & beta & S.E. & $\mathrm{AOR}^{1}$ & $95 \% \mathrm{CI}$ & beta & S.E. & $\mathrm{AOR}^{1}$ & $95 \% \mathrm{CI}$ & beta & S.E. & $\mathrm{AOR}^{1}$ & $95 \% \mathrm{CI}$ \\
\hline Year (1996) & 0.02 & 0.21 & 1.0 & $0.7-1.5$ & 1.06 & 0.32 & 2.9 & $1.5-5.5$ & 0.26 & 0.20 & 1.3 & $0.9-1.9$ & 0.72 & 0.24 & 2.0 & $1.3-3.3$ \\
\hline Gender (female) & 0.15 & 0.25 & 1.2 & $0.7-1.9$ & 0.11 & 0.38 & 1.1 & $0.5-2.3$ & 0.55 & 0.26 & 1.8 & $1.1-3.0$ & 0.48 & 0.31 & 1.6 & $0.9-3.0$ \\
\hline \multicolumn{17}{|l|}{ Age groups } \\
\hline $80-89$ & -0.81 & 0.26 & 0.4 & $0.3-0.7$ & -0.87 & 0.37 & 0.4 & $0.2-0.9$ & -0.10 & 0.27 & 0.9 & $0.5-1.5$ & 0.03 & 0.31 & 1.0 & $0.6-1.9$ \\
\hline $90+$ & -0.90 & 0.30 & 0.4 & $0.2-0.7$ & -0.89 & 0.45 & 0.4 & $0.2-0.98$ & 0.21 & 0.30 & 1.2 & $0.7-2.2$ & -0.45 & 0.37 & 0.6 & $0.3-1.3$ \\
\hline \multicolumn{17}{|l|}{ CDR-groups } \\
\hline CDR 1 & -0.11 & 0.29 & 0.9 & $0.5-1.6$ & -0.79 & 0.43 & 0.5 & $0.2-1.1$ & -0.10 & 0.25 & 0.9 & $0.6-1.5$ & -0.11 & 0.30 & 0.9 & $0.5-1.6$ \\
\hline CDR 2-3 & 0.26 & 0.27 & 1.3 & $0.7-2.2$ & -0.62 & 0.39 & 0.5 & $0.3-1.2$ & -0.71 & 0.28 & 0.5 & $0.3-0.8$ & -0.35 & 0.30 & 0.7 & $0.4-1.3$ \\
\hline \multicolumn{17}{|l|}{ Behaviour } \\
\hline Apathetic/passive & 1.02 & 0.32 & 2.3 & $1.5-5.2$ & 0.15 & 0.55 & 1.2 & $0.4-3.4$ & -0.03 & 0.31 & 1.0 & $0.5-1.8$ & 1.00 & 0.37 & 2.7 & $1.3-5.6$ \\
\hline Anxious & 1.27 & 0.29 & 3.6 & $2.0-6.3$ & 1.21 & 0.40 & 3.3 & $1.5-7.3$ & 0.46 & 0.26 & 1.6 & $0.96-2.6$ & 1.26 & 0.31 & 3.5 & $1.9-6.5$ \\
\hline Agressive/wandering & 1.82 & 0.34 & 6.1 & $3.2-12.0$ & 1.20 & 0.51 & 3.3 & $1.2-9.0$ & 0.18 & 0.35 & 1.2 & $0.6-2.4$ & 0.87 & 0.41 & 2.4 & $1.1-5.4$ \\
\hline \multicolumn{17}{|l|}{ Psychotropic drugs } \\
\hline Antipsychotics & $\mathrm{NA}^{2}$ & & & & -0.71 & 0.39 & 0.5 & $0.2-1.1$ & 0.11 & 0.24 & 1.1 & $0.7-1.8$ & 0.03 & 0.27 & 1.0 & $0.6-1.7$ \\
\hline Anxiolytics & -0.73 & 0.38 & 0.5 & $0.2-1.02$ & $\mathrm{NA}^{2}$ & & & & -0.87 & 0.40 & 0.4 & $0.2-0.9$ & 1.16 & 0.32 & 3.2 & $1.7-6.0$ \\
\hline Hypnotics & 0.13 & 0.24 & 1.1 & $0.7-1.8$ & -0.99 & 0.41 & 0.4 & $0.2-0.8$ & $\mathrm{NA}^{2}$ & & & & 0.42 & 0.26 & 1.5 & $0.9-2.5$ \\
\hline Antidepressants & 0.01 & 0.27 & 1.0 & $0.6-1.7$ & 1.20 & 0.33 & 3.3 & $1.8-6.3$ & 0.42 & 0.25 & 1.5 & $0.9-2.5$ & $\mathrm{NA}^{2}$ & & & \\
\hline
\end{tabular}

1) Adjusted odds ratio

2) Not applicable

\section{REFERENCES}

1. Nygaard HA, Breivik K, Bakke K, Brudvik E, Moe TJ. Dementia and work load evaluation. Compr Gerontol [A] 1987; 1 (2): 65-8.

2. Ray WA, Griffin MR, Schaffner W, Baugh DK, Melton LJ. Psychotropic drug use and the risk of hip fracture. N Engl J Med 1987; 316: 363-9.

3. Beardsley RS, Larson DB, Burns BJ, Thompson JW, Kamerow DB. Prescribing of psychotropics in elderly nursing home patients. J Am Geriatr Soc 1989; 37: 327-30.

4. Beers M, Avorn J, Soumerai SB, Everitt DE, Salem S. Psychoactive medication use in intermediate-care facility residents. JAMA 1988; 260: 3016-20.

5. Anderson M. Drugs prescribed for elderly patients in nursing homes or under medical home care. Compr Gerontol 1989; 3 (Suppl A+B): 8-15.

6. Nygaard HA, Brudvik E, Juvik OB, Pedersen WE, Rotevatn TS, Vollset Å. Consumption of psychotropic drugs in nursing home residents: a prospective study in patients permanently admitted to a nursing home. Int $J$ Geriatr Psychiatry 1994; 9: 387-91.

7. Nygaard HA, Bakke K, Brudvik E. Mental and physical capacity and consumption of neuroleptic drugs in residents of homes for aged people. Acta Psychiatr Scand 1989; 80: 170-3.

8. Behandling av psykiske problemer hos pasienter med demenssykdom. (Treatment of psychiatric problems in patients with dementia syndromes). Oslo: The Norwegian Medicines Control Authority, 1994.

9. Årsland D. Aggressive behaviour in dementia and its pharmacological treatment: a review. Nord J Psychiatry 1995; 49: 111-8.

10. Avorn J, Soumerai SB, Everitt DE, Ross-Degnan D, Beers MH, Sherman D, Salem-Schatz SR, Fields D. A randomized trial of a program to reduce the use of psychoactive drugs in nursing homes. N Engl J Med 1992; 327: 168-73.

11. Nygaard HA. Vett og uvett i demensomsorg. Alvorlige atferdsforstyrrelser hos aldersdemente - samarbeid mellom ulike fagfelt og instanser i helsevesenet. Sem: INFO-banken, Rapport nr. 15, 1995.

12. Hughes CP, Berg L, Danziger WL, Coben LA, Martin RL. A new clinical scale for staging of dementia. Brit $J$ Psychiatry 1982; 140: 566-72.

13. Adolfsson R, Gottfries CG, Nyström L, Winblad B. Prevalence of dementia disorders in institutionalized Swedish old people. Acta Psychiatr Scand 1981; 63: 225-44.

14. Guidelines for ATC-classification. NLN-publicaton No. 16. Uppsala: Nordic Council on Medicines, 1985. 
15. Nygaard HA, Naik M, Moen E, Munch M. Endringer i aldershjemklientellet i Bergen 1985-96. Tidsskr Nor Lageforen 1997; 117: 3533-5.

16. Rovner BW, Edelman BA, Cox MP, Shmuely Y. The impact of antipsychotic drug regulations on psychotropic prescribing practice in nursing homes. Am J Psychiatry 1992; 149: 1390-2.

17. Borson S, Doane K. The impact of OBRA-87 on psychotropic drug prescribing in skilled nursing facilities. Psychiatr Serv 1997; 48: 1289-96.

18. Weyerer S, El-Barrawy R, König S, Zimber A. Epidemiologie des Gebrauchs von Psychopharmaka in Altenheimen. Gesundheitswesen 1996; 58: 201-6.

19. Schneider LS, Pollock VE, Lyness SA. A metaanalysis of controlled trials of neuroleptic treatment in dementia. J Am Geriatr Soc 1990; 38: 553-63.

20. Gilleard EC, Morgan K, Wade BE. Patterns of neuroleptic use among the institutionalized elderly. Acta Psychiatr Scand 1983; 68: 419-25.

21. Connelly PJ. An audit of the use of antipsychotics in a geriatric psychiatry continuing care unit in Scotland. Int J Geriatr Psychiatry 1992; 7: 447-53.

22. Robinson RG, Bolduc P, Price TR. Two year longitudinal study of post-stroke mood disorders: diagnosis and outcome at 1 and 2 years. Stroke 1987; 18: 837-42.

23. House A, Dennis M, Molyneux A, Warlow C, Hawton K. Emotionalism after stroke. BMJ 1989; 298: $991-4$.

24. Snowdon J, Donelly N. A study of depression in nursing homes. J Psychiatr Res 1986; 20: 327-33. 